\title{
Facing the COVID-19 emergency: we can and we do
}

\section{Andrea Giovagnoni ${ }^{1}$}

Published online: 30 March 2020

(c) Italian Society of Medical Radiology 2020

As Editor-in-Chief of this journal and being personally involved as Chief of Radiology Department in a university Italian hospital within one of the major hotbeds of COVID19, I feel compelled to write an editorial about the Italian COVID-19 outbreak.

As already highlighted by many published scientific papers [1], diagnostic imaging has a pivotal role in the diagnosis and management of the patients affected by COVID-19.

Although the main Worldwide Guidelines [2] define the molecular tests on nasopharyngeal and oropharyngeal swabs as the reference standard for the diagnosis, chest $\mathrm{CT}$ remains the main method for evaluating the disease pulmonary extension and for follow-up.

Moreover, several papers, mostly on Chinese case series, have identified and defined the main patterns at chest $\mathrm{CT}$ of pulmonary involvement in COVID-19; thus, the Chinese authors themselves and the American College of Radiology (ACR) highly recommend to familiarize with the CT appearance of COVID-19 infection [3, 4].

For this purpose, the President of the Italian Society of Medical and Interventional Radiology (SIRMi) established a dedicated page on the SIRMi Web site with an Italian collection of COVID-19 imaging; in this way, the Italian radiologists, and not only, can freely access and become familiar with CT and radiographic images of anonymized COVID-19 cases collected form several Italian centers.

Nevertheless, alongside the assistance to the patients affected by COVID-19, which mainly lies on a prompt and accurate diagnosis, I care to highlight another aspect: the huge effort that has been required to all the health professional of the radiology departments.

Andrea Giovagnoni

a.giovagnoni@staff.univpm.it

1 Department of Radiology - Division of Special and Pediatric Radiology, University Hospital, Via Conca 71, 60126 Ancona, AN, Italy
So far, radiologists, radiographers, nurses, healthcare workers and administrative staff are daily fighting the COVID-19 emergency on the frontline.

The World Health Organization (WHO) developed a document [5] defining rights, roles and responsibilities of all the healthworkers for the COVID-19 emergency setting.

I would like to emphasize that WHO highlights not only the infective risk, but also the dramatic raise of the working hours for the healthworkers and therefore the growth of the psychological stress, of the fatigue and of risk of burnout for the whole health-working category.

It is highly desirable that this document will be received in the radiological field.

In these hard times, together with the medical and radiological skills that each of us must put into practice, we should not forget that behind healthworkers involved in all the Italian radiological departments, there are women and men from whom a huge personal effort is requested, an effort which is tremendous and unique even compared to wars, natural disasters and epidemics we dealt with during the last century.

The whole staff of La Radiologia Medica, the President and the whole Board of Direction of SIRMi are strongly supporting and thanks all the women and men working in the Italian radiology departments.

All together we can overcome this challenge!

\section{Compliance with ethical standards}

Conflict of interest The authors declare that they have no conflict of interest.

Ethical standards This article does not contain any studies with human participants or animals performed by any of the authors. 


\section{References}

1. Li Y, Xia L (2020) Coronavirus disease 2019 (COVID-19): role of chest CT in diagnosis and management. AJR Am J Roentgenol $4: 1-7$

2. Chinese Society of Radiology (2020) Radiological diagnosis of new coronavirus infected pneumonitis: expert recommendation from the Chinese Society of Radiology (First edition). Chin J Radiol 54(00):E001. https://doi.org/10.3760/cma.j.i ssn.1005-1201.2020.0001

3. Bai HX, Hsieh B, Xiong Z, Halsey K, Choi JW, Tran TML et al (2020) Performance of radiologists in differentiating COVID-19 from viral pneumonia on chest CT. Radiology 10:200823
4. https://www.acr.org/Advocacy-and-Economics/ACR-PositionStatements/Recommendations-for-Chest-Radiography-and-CTfor-Suspected-COVID19-Infection

5. https://www.who.int/docs/default-source/coronaviruse/who-right s-roles-respon-hw-covid-19.pdf?sfvrsn=bcabd401_0

Publisher's Note Springer Nature remains neutral with regard to jurisdictional claims in published maps and institutional affiliations. 